\title{
Eficiência da disseminação aérea em Pyricularia grisea ${ }^{1}$
}

\author{
Alfredo Seiiti Urashima², Sabrina Ferreira Leite ${ }^{2}$, Rafael Galbieri ${ }^{3}$,
}

Departamento de Biotecnologia Vegetal, Centro de Ciências Agrárias, Universidade Federal de São Carlos, Via Anhanguera Km 174, CEP 13600000 Araras, S.P., e-mail: alfredo@cca.ufscar.br. ${ }^{1}$ FAPESP Auxílio (04/09738-3); ${ }^{2}$ Bolsista CNPq/Pibic; ${ }^{3}$ FAPESP I.C. (03/06977-4)

Autor para correspondência: Alfredo S. Urashima

Data de chegada: 24/10/2005. Aceito para publicação em: 16/12/2006.

\section{RESUMO}

Urashima, A.S., Leite, S.F., Galbieri, R. Eficiência da disseminação aérea em Pyricularia grisea. Summa Phytopathologica, v.33, n.3, p.275$279,2007$.

Pyricularia grisea (teleomorfa Magnaporthe grisea) é um patógeno que infecta mais de 80 gramíneas. No Brasil ataca importantes culturas como arroz e trigo, causando a brusone. Mais recentemente foi reportada na triticale, cultura alternativa para os produtores de trigo no sul do estado de São Paulo. Um dos principais meios de disseminação da doença é a dispersão aérea embora pouca informação esteja disponível sobre a distância que esses esporos podem atingir a partir de uma determinada fonte de inóculo. O presente trabalho teve o objetivo de avaliar a capacidade de disseminação de $P$. grisea a partir de um foco inicial, empregando ferramentas moleculares. A presença de clones do patógeno em campos distantes 4, 30 e 1000 metros a partir de um campo infectado sugere que esporos de um determinado foco podem atingir pelo menos essas distâncias.

Palavras-chave adicionais: Magnaporthe grisea, DNA

\begin{abstract}
Urashima, A.S.; Leite, S.F.; Galbieri, R. Efficiency of aerial dissemination of Pyricularia grisea. Summa Phytopathologica, v.33, n.3, p.275$279,2007$.
\end{abstract}

Pyricularia grisea (teleomorph Magnaporthe grisea) infects more than 80 gramineous plants. In Brazil, it attacks important crops like rice and wheat causing blast disease. Recently the disease was reported in triticale, an alternative crop to wheat producers in Southern São Paulo state. Airborne conidia are one of the most important way of dissemination, although little reliable information is available on

Additional Keywords: Magnaporthe grisea, DNA

A brusone causada pelo fungo Pyricularia grisea (Cooke) Sacc. (telem. Magnaporthe grisea Barr.) é uma das doenças mais disseminadas e destrutivas entre os fungos fitopatogênicos. Esse patógeno se caracteriza por possuir uma ampla gama de hospedeiros englobando grande número de gramíneas ao redor do mundo (1). Dentre os hospedeiros desse fungo, o arroz (Oryza sativa L.) é o mais importante, sendo de ocorrência generalizada em praticamente todas as regiões produtoras do mundo. Ataque nos estádios de plântula ou no perfilhamento pode comprometer a cultura, assim como severas infecções nas panículas podem destruir a produção (14).

No Brasil, além do arroz, a brusone também foi constatada na cultura do trigo (Triticum aestivum L.) (5) e em lavouras de triticale (X. Triticosecale Wittmack) (11). No ano de 2001, a brusone atingiu extensas áreas de triticale no estado de São Paulo, com severos danos à produtividade, compreendendo a região de Capão Bonito, Itararé, Itapeva, Taquarituba e Avaré. A cultura do triticale vinha atraindo a atenção dos produtores da região graças ao menor custo de produção, por ser uma cultura que apresenta maior rusticidade que o trigo, por the distance traveled by spores from an inoculum source. The present work aimed to determine by molecular tools the efficiency of aerial dissemination of $P$. grisea from a known inoculum source. The presence of pathogen clones in fields distant 4, 30 and 1000 meters from an infected field suggested that spores can travel at least these distances.

não requer gastos com produtos químicos para o controle de doenças e por possibilitar boa produtividade. Assim, o aparecimento da brusone fez com que a cultura deixasse de ser uma boa alternativa ao trigo, visto que para evitar danos à produtividade, o controle químico passou a ser necessário, em função da ausência de variedades resistentes ao patógeno.

P. grisea é um patógeno policíclico, uma lesão é produzida em média 6 dias após a infecção e uma lesão típica é capaz de produzir 2.000 a 6.000 conídios por dia por aproximadamente 14 dias em condições de laboratório (14). A disseminação aérea é considerada o mais importante meio de dispersão da doença, embora ainda pouca informação esteja disponível sobre a distância que os esporos podem atingir a partir de uma determinada fonte de inóculo.

As ferramentas moleculares aliadas às técnicas convencionais podem contribuir para elucidar a capacidade de disseminação dos patógenos. Mizubuti \& Maffia (12) utilizaram a técnica de PCR ("Polymerase Chain Reaction") juntamente com os equipamentos coletores de esporos para fazer uma análise dos esporos aderidos à 
fita adesiva. Outra linha de pesquisa foi empregada por Zwankhuizen et al. (18) que utilizaram DNA "fingerpriting" para comparar os genótipos de Phytophthora infestans em campos comerciais de batata com os genótipos encontrados em potenciais fontes de inóculo para determinar com precisão a fonte de inóculo inicial. Na brusone do arroz, Ishiguro et al. (6) também empregou DNA "fingerprinting" em estudo de dispersão do patógeno e observaram que esporos de $P$. grisea foram encontrados causando lesões de brusone à distância de pelo menos 700 metros da fonte de inoculo. Distâncias maiores não foram estudadas.

O conhecimento da distância que esporos podem percorrer a partir de uma determinada fonte de inóculo é essencial para delinear estratégias apropriadas de manejo de doenças que incluam erradicação de inóculo, aplicação de fungicida e dinâmica populacional do patógeno. Assim, o objetivo do presente trabalho foi avaliar a distância que esporos de $P$. grisea podem percorrer a partir de um determinado campo infectado.

\section{MATERIAL E MÉTODOS}

A existência ou não do fluxo de genes em $P$. grisea foi examinada através de ferramentas moleculares em análise direta. Nesse exame, verifica-se a movimentação de indivíduos com o mesmo perfil genético entre populações (12). Para se atingir esse objetivo a seguinte metodologia foi empregada:

\section{Campos de origem}

Os isolados foram oriundos de quatro campos de triticale com algumas características que favoreceram os objetivos do presente projeto, a saber: 1) todos os campos tinham sido os primeiros a serem semeados no ano agrícola de 2003. Assim, houve uma probabilidade maior que a fonte de inóculo primário tenha se restringido a um único foco já que os outros campos ao redor apresentavam-se sadios; 2) os campos encontravam-se em estádio inicial da doença, o que possibilitou a coleta da totalidade das espigas doentes, com um mínimo de escape; 3) os campos infectados estavam localizados a distâncias variáveis, o que permitiu estudar a existência e a eficácia da disseminação aérea nos diferentes campos.

Além destes aspectos comuns, cada campo apresentava algumas características próprias, a saber:

a) O campo denominado 1 estava semeado com triticale da variedade Embrapa 53, sendo o seu segundo ano de plantio. Como dos campos estudados era o que se apresentava com a maior incidência da doença, foi considerado a fonte de inóculo primário para outros campos. Deste, foram coletadas 68 espigas e seus isolados denominados TTTQ01.

b) O campo 2 estava semeado com a variedade Embrapa 53, sendo o primeiro plantio neste campo. Se encontrava a 4 metros de distância do campo 1 e com baixa incidência da doença. Trinta e sete espigas foram coletadas e denominadas TTTQ02.

c) O campo 3 estava afastado 20-30 metros do campo 1, estando semeado também com a variedade Embrapa 53. Foram coletadas 56 espigas deste campo, cujos isolados foram denominados TTTQ03.

d) O campo 4 estava distante aproximadamente $1 \mathrm{~km}$ em linha reta do campo 1 e semeado com triticale BRS148. Deste, foram recolhidas 75 espigas e seus isolados denominados TTTQ04.

\section{Patógeno}

As espigas coletadas foram identificadas no campo e levadas posteriormente para laboratório onde sofreram esterilização superficial para em seguida serem submetidas às condições favoráveis de temperatura e umidade para esporulação e posterior isolamento monospórico. Após identificação dos isolados, estas foram preservadas em tubo de ensaio com meio BDA (Batata Dextrose Agar) para preservação por curto período. Para preservação a longo período, os isolados foram inoculados em tubos de ensaio contendo sementes de trigo autoclavadas e após sua colonização completa, colocadas em vasilhames contendo sílica gel e estocadas a $4{ }^{\circ} \mathrm{C}$ no Laboratório de Genética Molecular do CCA, UFSCar, Araras.

\section{Extração de DNA}

DNA foi extraído de acordo com a metodologia descrita por Urashima et al. (16). Isolados foram incubados em meio CM (3 g de acido casamino, $3 \mathrm{~g}$ de extrato de levedura, $5 \mathrm{~g}$ de sucrose/litro) sob rotação constante a $25^{\circ} \mathrm{C}$ por 6 a 7 dias. Em seguida o micélio foi recolhido, filtrado e lavado para extração de DNA genômico. O micélio ( 3 a 4 gramas de peso fresco) foi moído em nitrogênio líquido, suspenso em $4 \mathrm{ml}$ de tampão de extração (1\% sarkonil, $0,25 \mathrm{M}$ sucrose, $50 \mathrm{mM}$ $\mathrm{NaCl}, 20 \mathrm{mM}$ EDTA, $50 \mathrm{mM}$ Tris-Cl pH 8,0 e $10 \mathrm{mM}$ Mercaptoetanol) por $40 \mathrm{~min}$. A solução foi em seguida misturada com igual volume de fenol e centrifugada por $20 \mathrm{~min}$ a $3000 \mathrm{rpm}$. A fase aquosa foi coletada e misturada com igual volume de fenol/clorofórmio/ isoalcool $(25: 24: 1, \mathrm{v} / \mathrm{v} / \mathrm{v})$ e centrifugada por $25 \mathrm{~min}$ a $3000 \mathrm{rpm}$. Ao sobrenadante extraído, foram adicionados ácido sódio acético $(1: 10, \mathrm{v} /$ v) e igual volume de isopropanol e em seguida incubado por $30 \mathrm{~min}$ a $-70^{\circ} \mathrm{C}$ e centrifugado por $10 \mathrm{~min}$ a $3000 \mathrm{rpm}$ após o qual o ácido nucléico foi coletado. Os "pellets" foram dissolvidos em $1 \mathrm{ml}$ de solução tampão TE (10 mM Tris-Hcl pH 8,0 e 0,1 mM EDTA). Posteriormente, o DNA foi purificado incubando-o com $5 \mu$ lde RNase $(10 \mathrm{mg} / \mathrm{ml})$ a $37^{\circ} \mathrm{C}$ por $4 \mathrm{~h}$. Em seguida, os "pellets" foram lavados em álcool $70 \%$, secos e dissolvidos em $50 \mathrm{ml}$ de solução tampão TE.

\section{Digestão de DNA, eletroforese e análises de "Southern blot"}

Foi utilizada a metodologia descrita por Urashima et al. (16). Um micrograma de DNA genômico foi digerido com enzimas de restrição (HindIII) e separado por eletroforese em gel de agarose (1\%) em tampão $0,5 \mathrm{XTBE}$ por $17 \mathrm{~h}(33 \mathrm{~V}, 30 \mathrm{~mA})$. Os fragmentos de DNA resultantes foram desnaturados e transferidos por capilaridade para membrana de "nylon". A pré e a hibridização dessas membranas foram feitas em solução 6 X SSC contendo $5 \mathrm{X}$ solução Denhardt mais $0,5 \%$ SDS e DNA de esperma de salmão em plásticos selados a $68^{\circ} \mathrm{C}$ por 12 a 15 h. Após, a hibridização as membranas foram lavadas em solução $2 \mathrm{X}$ SSC, $0,1 \%$ SDS e $0,1 \mathrm{X}$ SSC, $0,1 \%$ SDS. O DNA foi detectado por quimiluminescência usando Phototope ${ }^{\mathrm{TM}}$ Star Detection Kit (New England Biolabs) e fotografados após coloração com brometo de etídio.

\section{Analise da estrutura populacional}

O DNA “fingerprinting” foi construído após avaliação visual da presença ou ausência da banda em cada loco. Os dados foram analisados usando-se o programa NTSYS. As distâncias genéticas foram calculadas pelo coeficiente de similaridade Russel. A análise dos clusteres e a construção dos fenogramas baseados no coeficiente de similaridade utilizando-se UPGMA ("unweighted pair-group method with arithmetic mean").

A robustez do dendograma foi analisada pelo programa BOOTSTRAP com 3000 repetições.

\section{RESULTADOS}

Seis diferentes dendrogramas de similaridade empregando isolados dos campos 1, 2, 3 e 4 foram gerados a partir de seis DNA "fingerprinting" com diferentes isolados de cada campo. Um desses 
DNA "fingerprinting" que geraram esses dendrogramas é mostrado na Figura 1. Cinco isolados do campo 1, três do campo 2, quatro do campo 3 e quatro do campo 4, após digestão com HindIII, geraram 29 fragmentos polimórficos variando de $0,5 \mathrm{~kb}$ a $10 \mathrm{~kb}$. De todos os isolados, o TTTQ03-14 (poço 9) foi o que se distinguiu por apresentar um padrão genético distinto dos demais com um número menor de bandas (10), enquanto os outros isolados apresentaram padrão genético semelhante, com número de fragmentos variando de 19 a 22.

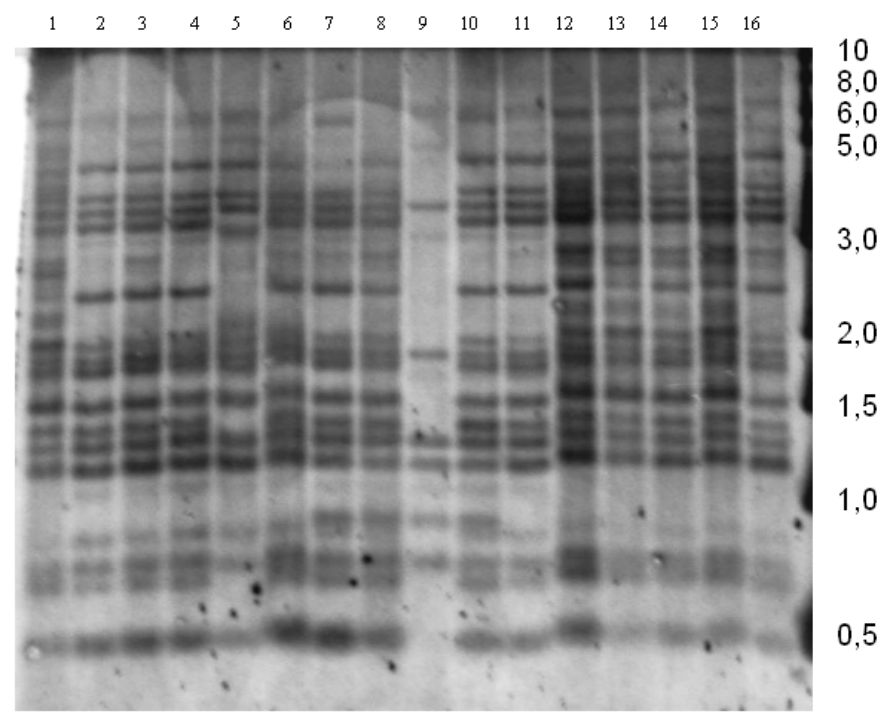

Figura 1. DNA fingerprinting de isolados de Pyricularia grisea de diferentes campos de triticale. DNA foi digerido com HindIII e hibridizado com Pot2. Os poços contêm DNA dos isolados: 1:TTTQ01.03, 2: TTTQ01.14, 3:TTTQ01.17, 4:TTTQ01.20, 5:TTTQ 01.22, 6:TTTQ02.01, 7:TTTQ02.07, 8: TTTQ02.05, 9:TTTQ 03.14, 10:TTTQ03.02, 11:TTTQ03.21，12:TTTQ03.03， 13:TTTQ04.04， 14:TTTQ04.05, 15:TTTQ04.19, 16:TTTQ04.10. Marcadores moleculares (Kb) estão indicados no lado direito.

Devido a dificuldade de análise baseada em observação visual, os dados gerados no DNA "fingerprinting" foram transformados em dendrogramas de similaridade a partir das avaliações visuais da presença/ ausência de banda em cada loco do DNA "fingerprinting". Embora em todos os dendrogramas produzidos, isolados com $100 \%$ de similaridade tenham-se sido detectados, duas situações distintas foram observadas: uma representada pelas Figuras 2 e 7 onde o valor "bootstrap" foi alto (95,3\% na Fig. 2 e 92,3\% na Fig. 7, respectivamente) e a outra com valores "bootstrap" baixos ou não robustos, conforme Figuras 3, 4, 5 e 6 , onde análises mais detalhadas não são apoiadas por valores de confiança altos.

Dentre os dendrogramas que apresentaram baixo "bootstrap", a Figura 3 mostra um isolado do campo 01 (TTTQ01-14), um do campo 03 (TTTQ03-03) e cinco do campo 04 (TTTQ04-10, 04-13, 04-14, 04-15, 04-23) com o mesmo perfil genético, ou seja, são clones com $100 \%$ de similaridade. O mesmo pode ser observado na Figura 5 com dois isolados do campo 02 (TTTQ01-07 e 01-08), três do campo 03 (TTTQ03-06, 03-11 e 03-15) e dois isolados do campo 04 (TTTQ0403 e 04-09). Já na Figura 4 uma outra situação foi verificada, qual seja, a ocorrência de clones entre isolados do mesmo campo: TTTQ01-17 e 01-20 no campo 01, TTTQ02-05 e 02-07 no campo 2 e dos isolados TTTQ04-05 e 04-19 no campo 4. A distância genética entre esses grupos variou de aproximadamente 76 a $90 \%$.

Analises mais detalhadas e com uma confiabilidade maior podem ser feitas com as Figuras 2 e 7 que apresentaram altos valores

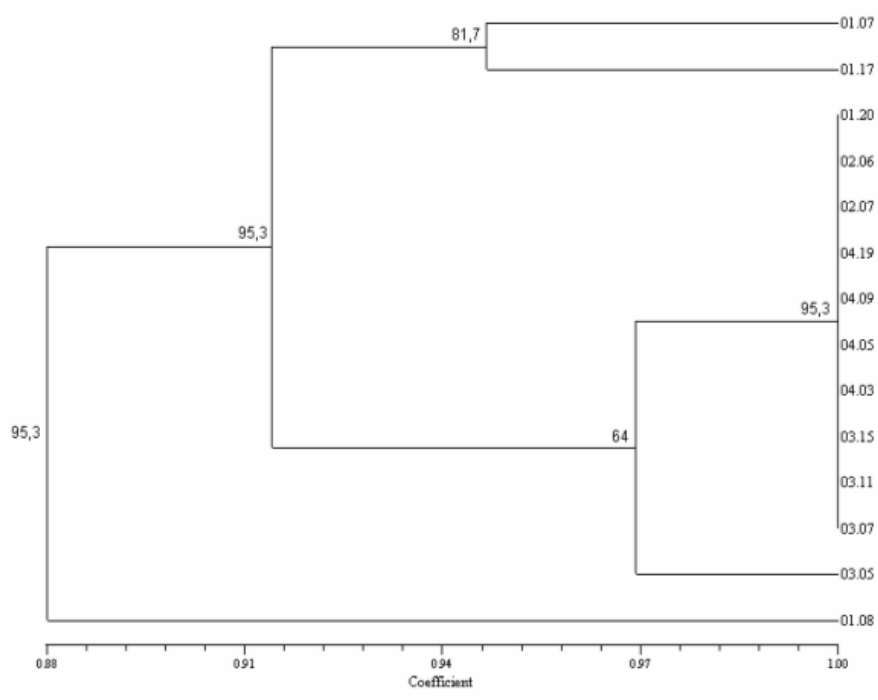

Figura 2. Dendrograma UPGMA de isolados de Pyricularia grisea de quatro campos de triticale (conjunto A)

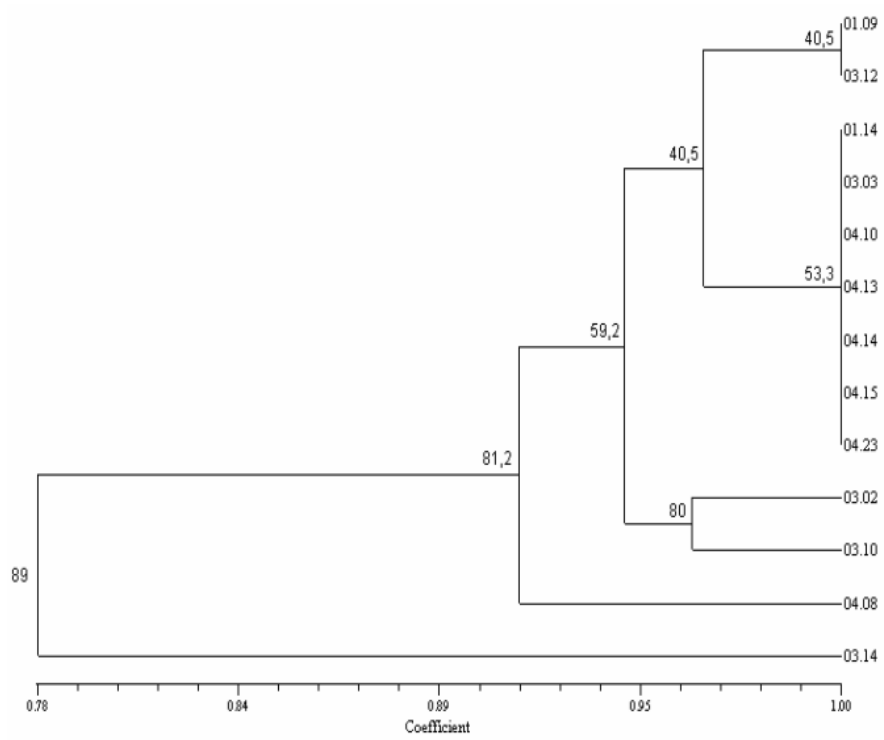

Figura 3. Dendrograma UPGMA de isolados de Pyricularia grisea de quatro campos de triticale (conjunto B)

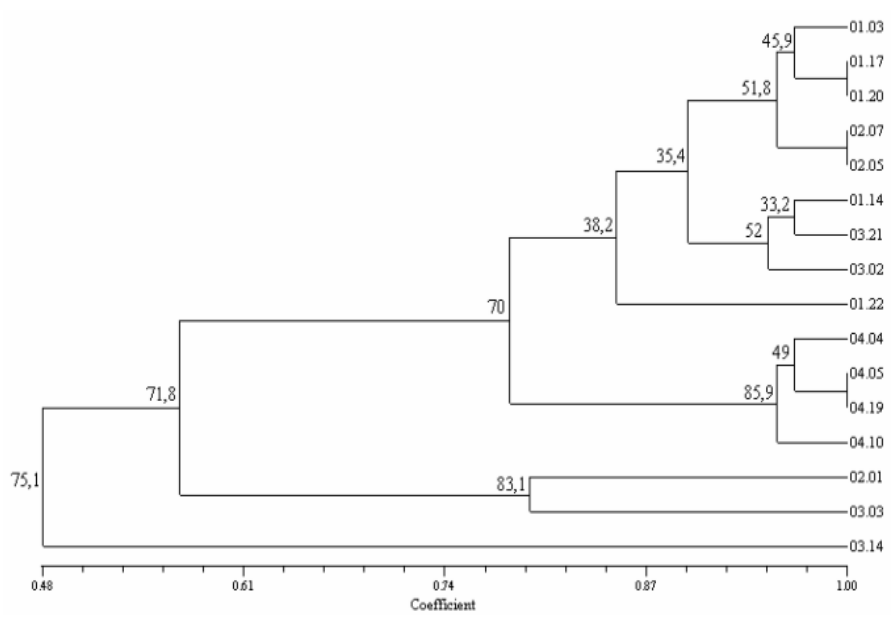

Figura 4. Dendrograma UPGMA de isolados de Pyricularia grisea de quatro campos de triticale (conjunto $\mathrm{C}$ ) 


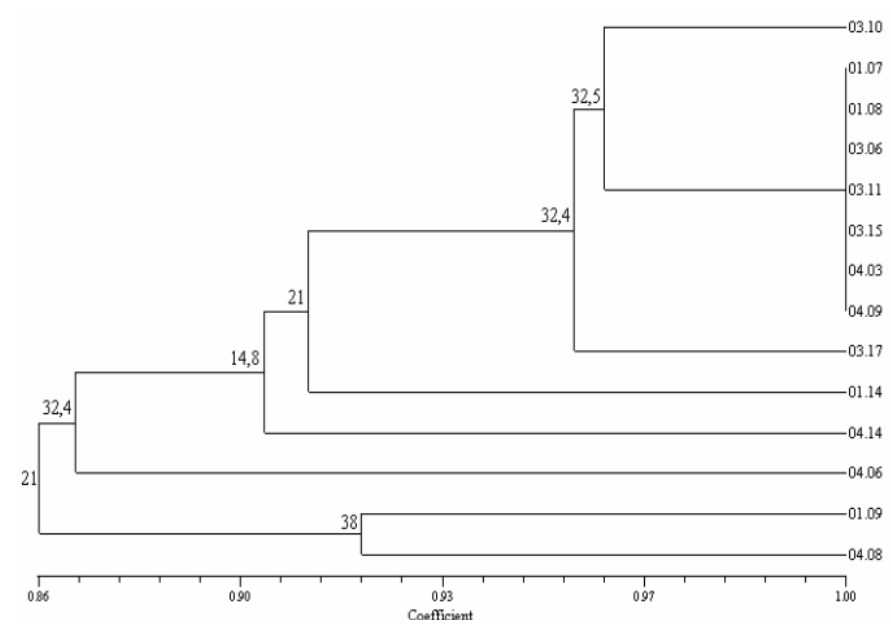

Figura 5. Dendrograma UPGMA de isolados de Pyricularia grisea de quatro campos de triticale (conjunto D)

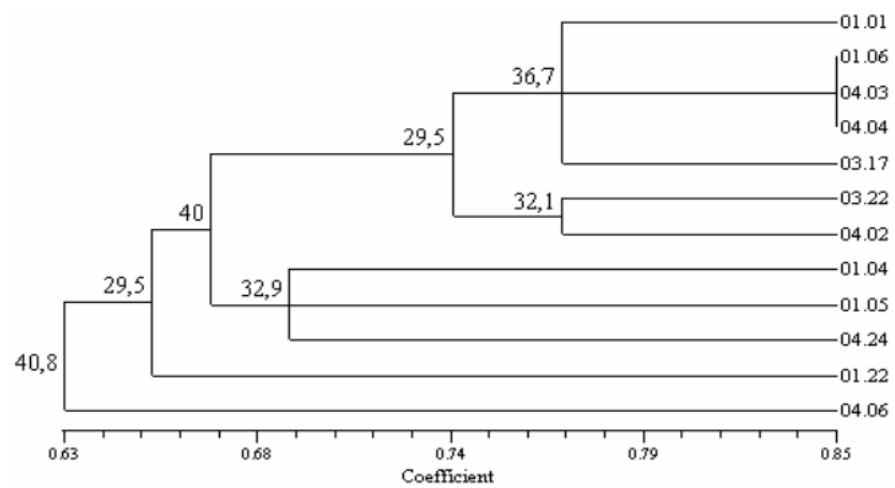

Figura 6. Dendrograma UPGMA de isolados de Pyricularia grisea de quatro campos de triticale (conjunto E)

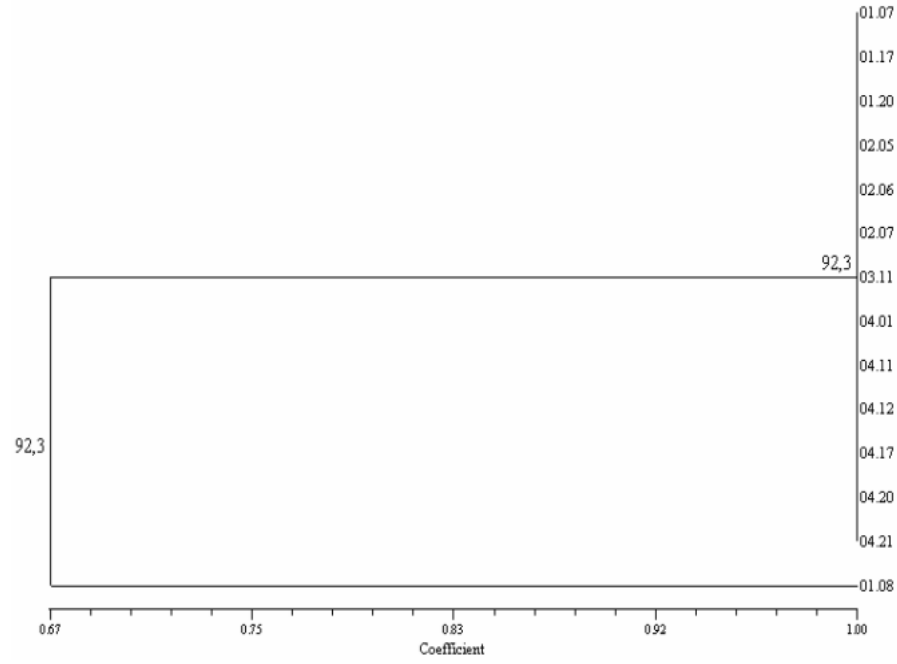

Figura 7. Dendrograma UPGMA de isolados de Pyricularia grisea de quatro campos de triticale (conjunto F)

"boostrap" (95,3 e 92,3\%, respectivamente). Dos 14 isolados analisados, 10 apresentaram-se com $100 \%$ de similaridade (Figura 2). Todos os campos estavam representados: 1 isolado do campo 01 (TTTQ01-20), dois do campo 02 (TTTQ02-06 e 02-07), três do campo 03 (TTTQ03-07, 03-11, 03-15) e quatro do campo 04 (TTTQ04-03, 04-05, 04-09, 04-19). Os outros quatro isolados restantes apresentaram similaridade variando de 88 a 97\%. Para essas análises, 20 bandas polimórficas foram avaliadas no DNA “fingerprinting” com esses isolados (dado não mostrado). Maior número de clones foi identificado na Figura 7, com 13 isolados dentre os 14 analisados. Também aqui, os clones provinham dos quatro campos: três do campo 01 (TTTQ01-07, 01-17,01-20), três do campo 02 (TTTQ02-05, 02-06, 02-07), um do campo 03 (TTTQ-3-11) e seis do campo 04 (TTTQ04-01, 04-11, 04-12, 04-17, 04-20, 04-21), sendo analisadas 6 bandas polimórficas.

\section{DISCUSSÃO}

Resultados do presente trabalho mostraram que a disseminação de esporos de $P$. grisea é um fenômeno comum e um importante fator de dispersão da doença para outros campos. No presente estudo, três campos localizados a distâncias variáveis do campo foco inicial da doença foram estudados, um a curta distância (4-5 metros) denominado de campo 2, outro a média (20-30 metros) que foi o campo 3 e um terceiro a longa distância $(1 \mathrm{~km})$ (campo 4) e, em todas as situações foram detectados presença de isolados clones de P. grisea. Segundo Boeger et al. (2), três são as razões principais para a detecção de clones entre campos geograficamente distantes: dispersão aérea de propágulos, hospedeiros alternativos e sementes contaminadas. A possibilidade de sementes contaminadas tenham sido as responsáveis pela disseminação do patógeno é remota, pois diferentes variedades foram empregadas (campo 4 e campo 01) com conseqüente uso de diferentes sementes. Para campos semeados com a mesma variedade (campo 01, 02 e 03), alguns fatores contribuíram para deduzir que a disseminação de $P$. grisea via sementes é nula e garantir a eficiência dos testes realizados. Por exemplo, o fato da disseminação do patógeno em sementes de arroz ser baixa $(4,9,10)$, confirmado posteriormente por Dias Martins \& Urashima (3) que, mesmo empregando sementes de triticale comprovadamente infectadas pelo patógeno e sob condições favoráveis ao desenvolvimento do fungo, obtiveram $35 \%$ de plântulas sadias sem sintomas da doença. Outro fator que pode ser acrescentado é que sementes chochas resultantes do ataque de $P$. grisea são eliminadas no processo de limpeza e secamento (10) e o mais importante é que não se observou lesões de brusone nas folhas que são os locais de aparecimento de sintomas em caso de transmissão do patógeno pelas sementes.

Ervas daninhas poderiam ter atuado como hospedeiros alternativos do patógeno e disseminar a doença por meio de dispersão aérea a curtas distâncias de forma contínua e consecutiva. Para que isso se confirmasse deveria ter sido constatada a existência de ervas com sintomas da brusone nos campos estudados. Embora ervas daninhas possam ser infectadas por $P$. grisea (17), investigação detalhada e minuciosa desses campos, não resultou na localização de nenhum hospedeiro com sintomas da doença.

Por outro lado, disseminação de propágulos via dispersão aérea direta a longas distâncias é considerada um dos principais meios de disseminação de doenças. Neste aspecto, as ferrugens foram bem estudadas, sendo que para a ferrugem da folha do trigo (Puccinia recôndita f.sp. tritici) foi verificada que a população que atacou plantações de trigo nas províncias de Quebec e Ontario, no Canadá, foram originadas de patógenos que migraram de Kansas e Oklahoma, nos Estados Unidos (8). A ferrugem do café (Hemileia vastatrix) atingiu a Bahia a partir de vôos transoceânicos de Angola na África (13). Entretanto, com relação a brusone, pouco se sabe sobre a dispersão dos esporos de $P$. grisea pelo ar a longas distâncias. Embora a maioria dos esporos seja encontrado a 1 metro da fonte de inóculo (14), poucos trabalhos determinaram com precisão a distância percorrida pelo 
patógeno a partir de uma fonte de inóculo pré-determinado. Isso porque experimentos empregando coletores de esporos (15) são trabalhosos na sua execução em função da dificuldade em se diferenciar esporos patogênicos dos não patogênicos (7), além da impossibilidade de separar e identificar as fontes de inóculo dos esporos coletados.

$\mathrm{O}$ advento das modernas técnicas moleculares veio permitir que estudos sobre a dispersão ou disseminação dos esporos os quais vinham sendo feitos por meio de caça-esporos fossem substituídos pela análise genética do isolados. Assim, a ocorrência do mesmo perfil genético entre campos demonstra com precisão não alcançada até então, que o mesmo isolado do patógeno está ocorrendo em campos distintos. Esta técnica foi empregada por Zwankhuizen et al. (18) para mostrar que batatas descartadas, porém mantidas no campo de produção (refugos) eram o foco inicial de epidemias de requeima (P. infestans). Outro trabalho empregando a mesma metodologia foi realizado por Ishiguro et al. (6) com P. grisea para determinar que o esporo foi capaz de percorrer até 700 metros de distância entre a palhada deixada no campo de arroz (fonte de inóculo primário da doença) e a primeira geração da doença em plântulas de arroz. O presente trabalho embora empregue o mesmo patógeno difere daquele, pois os pesquisadores japoneses conduziram seus estudos em terras baixas de cultivo irrigado de arroz. O presente trabalho verificou a distância percorrida pelo patógeno em terras altas de cultivo de triticale em sequeiro.

O campo 1 foi o primeiro a ser atacado pela brusone, por estar com um incidência maior e num estádio mais avançado da doença, e clones do patógeno foram identificados nos demais campos. Embora não se possa afirmar com precisão que a fonte de inóculo primário para a doença nos campos 2, 3 e 4 tenha se originado do campo 1, pode-se afirmar que esporos deste campo percorreram diferentes distâncias atingindo até $1 \mathrm{~km}$, mostrando alta eficiência de disseminação para esporos de $P$. grisea.

Esse é um estudo pioneiro para avaliar a dispersão de esporos de fungo empregando técnicas moleculares no Brasil. O presente trabalho é o primeiro a demonstrar que esporos de $P$. grisea podem atingir campos distantes a pelo menos $1 \mathrm{~km}$ do foco da doença e indica que qualquer estratégia de controle da brusone tem que levar essa distância em consideração.

\section{REFERÊNCIAS BIBLIOGRÁFICAS}

1. Asuyama, H. Morphology, taxonomy, host range, and life cycle of Pyricularia oryzae. In: Ou, S.H. (ed.) The rice blast disease. Baltimore: Johns Hopkins Press, 1965. p.9-22.

2. Boeger, J.M.; Chen, R.S.; McDonald, B.A. Gene flow between geographic populations of Mycosphaerella graminicola (anamorph Septoria tritici) detected with Restriction Fragment Length Polymorphism markers. Phytopathology, St. Paul, v.83, p.11481154, 1993.
3. Dias Martins, T.; Urashima, A.S. Comparação entre métodos de avaliação de transmissão de Pyricularia grisea através de sementes em triticale. Fitopatologia Brasileira, Brasília, v.29, p.425$428,2004$.

4. Goulart, A.C.P; Paiva, F.A. Controle de Pyricularia oryzae e Helminthosporium sativum pelo tratamento de sementes de trigo com fungicidas. Pesquisa Agropecuária Brasileira, Brasília, v.26, p.1983-1988, 1991.

5. Igarashi, S.; Utiamada, C.M.; Igarashi, L.C.; Kazuma, A.H.; Lopes, R.S. Pyricularia em trigo. 1. Ocorrência de Pyricularia sp. no estado do Parana. Fitopatologia Brasileira, Brasília, v.11, p.351 352, 1986 .

6. Ishiguro, K.; Harasawa, R.; Kobayashi, T. DNA fingerprinting reveals how rice blast disease spreads spatially within the local area. In: International Rice Blast Conference, 3., 2002, Tsukuba, Japan. Abstracts, Tsukuba: MEXT, 2002. p.136.

7. Kingsolver, C.H.; Barksdale, T.H.; Marchetti, M.A. Rice blast epidemiology. The Pensilvania State University, College of Agriculture, Bulletin 853, 1984.

8. Kolmer, J.A. Diversity of virulence phenotypes and effect of host sampling between and within populations of Puccinia recondita f.sp. tritici in Canada. Plant Disease, St. Paul, v.76, p.618$621,1992$.

9.Lamey, H.A. Pyricularia oryzae on rice seed in the United States. Plant Disease Report, St. Paul, v.54, p.931-935, 1970.

10.Manandhar, H.K.; Lyngs Jorgensen, H.J.; Smerdegaard-Peterse V.; Mathur, S.B. Seedborne infection of rice by Pyricularia oryzae and its transmission to seedlings. Plant Disease, St. Paul, v.82, p.1093-1099, 1998.

11. Mehta, Y.R.; Baier, A. Variação patogênica entre isolados de Magnaporthe grisea atacando triticale e trigo no estado do Paraná. Summa Phytopathologica, Botucatu, v.24, p.119$125,1998$.

12. Mizubuti, E.S.G.; Maffia, L.A. Ferramentas moleculares em estudos epidemiológicos. Revisão Anual de Patologia de Plantas, Passo Fundo, v.10, p.249-287, 2002.

13. Nagarajan, S. Long-distance dispersion of rust pathogens. Annual Review of Phytopathology, St. Paul, v.28, p.139-153, 1990.

14. Ou, S. H. Blast. In: Ou, S. H. Rice diseases. 2nd ed. Wallingford, UK: CAB International, 1985. p.109-201.

15. Suzuki, H. Behavior of rice blast fungus spore and application to outbreak forecast of rice blast disease. Japan Agriculture Research Quarterly, v.8, p.78-83, 1974.

16. Urashima, A.S.; Hashimoto, Y.; Don, L.D.; Kusaba, M.; Tosa, Y.; Nakayashiki, H.; Mayama, S. Molecular analysis of the wheat blast population in Brazil with a homolog of retrotransposon MGR583. Annals of the Phytopathological Society of Japan, Tokyo, v.65, p.429-436, 1999.

17. Urashima, A.S.; Kato, H. Pathogenic relationship between isolates of Pyricularia grisea of wheat and other hosts at different host developmental stages. Fitopatologia Brasileira, Brasília, v.23, p.30-35, 1998.

18. Zwankhuizen, M.J.; Govers, F.; Zadocks, J.C. Development of potato late blight epidemics: disease foci, disease gradients, and infection sources. Phytopathology, St. Paul, v.88, p.754-763, 1998. 